possible by: the use as solvent of "ultra-pure" water with a specific conductivity of $0.05-0.07 \times 10^{-6}$ reciprocal obm. The uncertainty attached to measurements in high dilution owing to impurities in the solvent is thus practically eliminated, as the water correction for 0.00007 and 0.00002 molar solutions is only 0.7 per cent. and 2.5 per cent, respectively. From their results Washburn and Weiland draw the important conclusion that the law of massaction applies between the concentrations 0.00002 and 0.00007 molar, the constant, $k$, of the dilution formula, $\boldsymbol{\alpha}^{2} c /(\mathrm{I}-\boldsymbol{\alpha})=k$, having the value 0.02 at $18^{\circ}$; between 0.00007 molar and 0.001 molar $k$ increases regularly up to a value of $0.05^{2}$ at the latter concentration. Although it is true that the concentration of the undissociated part, $I-\alpha$, is very small in these high dilutions, yet the accuracy of the measurements is such that the applicability of the dilution law up to 0.00007 molar may be regarded as established. Prof. Arrhenius and others had previously expressed the opinion that the law of mass-action is valid for strong electrolytes in sufficiently dilute solution, but this conclusion was open to doubt on account of the uncertainty in the correction for the conductivity of the solvent. At the meeting considerable difference of opinion was expressed on the question as to whether the validity of the mass law for strong electrolytes in sufficiently dilute solution can be proved by thermo-dynamical reasoning.

The results just described would appear to throw some light on the cause of the deviation of strong electrolytes from the mass law. The fact that the deviation appears in such high dilutions is difficult to reconcile with any explanation based on association between solvent and solute, as this would involve hydration values so great as to be in the highest degree improbable.

Walden and others ascribe the deviation to increased ionising power of the solvent owing to the presence of the electrolyte, and also to the effect of the electrolyte in increasing the ionisation of the solvent. Dr.J. W. McBain and Mr. F. C. Coleman showed in a paper published some years ago that there is no definite evidence of the supposed effect of salts in increasing the ionising power of water, and they show in a contribution to the present discussion, on the basis of migration experiments, that salts do not increase the ionisation of water. The latter conclusion is supported by the fact that the same value is obtained for the dissociation constant of water as determined by different methods, salts being present in some cases, but not in others.

The consideration of the above and other suggested explanations shows that the problem of strong electrolytes is not yet solved, but much may be hoped from the continuation of investigations, such as those of Washburn, with highly purified solvents. 'The question of inter-ionic forces also deserves careful study, and in this connection a theoretical contribution to the discussion by Dr. S. R. Milner will be read with interest.

Mr. Ghosh (Trans. Chem. Soc., I9I8) has recently put forward the view that salts are completely ionised in solution, and that the apparent increase of the molecular conductivity with dilution is due to the operation of electrical forces. On this basis he obtains a formula which permits of the calculation, from known data and a knowledge of the dielectric constant of the solvent, of the ionisation of a salt at a particular dilution and temperature. Dr. J. R. Partington, in an interesting contribution to the discussion, has critically examined Mr. Ghosh's theory, and draws the conclusion that his fundamental assumption, that only electrical forces are operative in the solution, is disproved.

The view formerly held by many supporters of the ionisation theory that only the ions of an electrolyte can react has now been abandoned, since it has been shown independently by Dr. Senter and by Prof. Acree that both ions and undissociated molecules are chemically active. Another aspect of the same subject which has received much attention in recent years is the suggestion that the catalytic activity of strong acids is due partly to $\mathrm{H}^{\prime}$ ions and partly to the undissociated molecules of the acid. If it be accepted that the catalytic effect of acids is a chemical action, this is simply a special case of the chemical activity of non-ionised molecules and their ions. A plausible explanation is thus afforded of the well-known fact that neutral salts accelerate the catalytic activity of strong acids.

Prof. Arrhenius considers the latter question in his contribution to the discussion, but favours an explanation of the accelerating effect of foreign substances based on the assumption that these substances increase the osmotic pressure of the reacting substances, and that the chemical reactivity of the latter is proportional to their respective osmotic pressures. The available experimental data do not allow this interesting suggestion to be tested adequately.

G. S.

\section{THE INHERITANCE OF MILK AND FAT PRODUCTION IN CATTLE.}

$A \mathrm{~T}$ the Maine Agricultural Experiment Station $\mathrm{Mr}$. A John W. Gowen has made a genetic study of the first-generation crosses of prominent dairy breeds of cattle and beef-bred Aberdeen-Angus. This work, the results of which are published in the Journal of Agricultural Research (vol. xv., October, 1918, pp. $\mathrm{I}^{-57}, 6$ plates), was undertaken as a link in the chain of evidence necessary to the final solution of the problems which are connected with the inheritance of milk production and butter-fat production. A cross-bred herd is being formed at the experiment station so as to provide as much material as possible for the analysis of the laws of heredity concerned with the productivity referred to, and this herd has now gone into its second generation.

An indication may be given of some of the important results already reached by Mr. Gowen :-

(I) Black body colour is dominant to the other colour in the first generation. In the second generation an orange-coated bull and a dark Jersey duncoated heifer were segregated out.

(2) White marking of the body, taken as a whole, appears as a dominant. Study of individual white areas, however, indicates that this is due to white in the inguinal region only, for this alone appears as such a dominant. White spots on the face, neck, shoulders, rump, fianks, and legs are generally suppressed in the offspring when the white-spotted individuals are mated to solid colour.

(3) Pigmented muzzle is dominant to one not so pigmented.

(4) A pigmented tongue is dominant to a nonpigmented one-a confirmation of a previous result.

(5) A black switch appears to cause the suppression of the other switch colours in the offspring.

(6) Some exceptions were found to the previously accepted hypothesis of simple dominance of polled. ness over the horned condition, and it is suggested that a hormone secreted by the testes may have some influence on the presence or absence of horns. Should this prove true, it would establish an interesting parallel between cattle and sheep, for in the latter a sex hormone is known to affect the development of the horns.

(7) The qualities of beef production are shown to be divisible into four general regions of the body:

NO. 2570 , VOI. IO2] 
head, forequarters, barrel, and hindquarters. When either parent is of Aberdeen-Ingus breed the offspring show the characteristic type of head and heavy, deepfleshed forequarters. The body and hindquarters appear intermediate, but resemble most the dairy parents. From his results so far the author concludes that for the improvement of the beef qualities of dairy breeds the first-generation crosses show an increased value of the beef qualities in the forequarters without materially influencing the hindquarters.

(8) A few data are supplied as to the production of milk and butter-fat by some of the cross-breds. The results indicate that milk and fat production behave separately in inheritance. High milk production is dominant to low, but, unfortunately, a high fat percentage in the milk is recessive to a low fat percentage. The author supplies a useful bibliography and numerous illustrations.

\section{SOME DEVELOPMENTS IN INDUSTRY DURING THE WAR. ${ }^{1}$}

Mica.-The electrical industry has proved to be a great war industry. It is bound to become an even greater peace industry. Previous to the war Germany had established a predominant position in this industry, but this would not have been possible without the supplies of mica brought from India and other parts of the British Empire.

Mica is absolutely essential to the electrical industry, and the position of the British Empirc in regard to mica supplies was, and is, far and away the strongest of any country in the world. India produces 50 per cent. of the world's supply of mica, and Canada I 5 per cent. Germany within her own Empire obtained Io per cent. of the world's supply, this being found in German East $\Lambda$ frica. But, in spitc of the overwhelming national advantages of our position at the outbreak of war, the mica market of the world was at the point of being transferred from London to Hamburg, thanks to the skill with which Germany had obtained a large measure of control of the Indian mines and the success with which she had captured the electrical industry. The Indian mica was either exported direct to Germany (she took 47,000 cwt. in 1913 ) or reexported from this country to Germany, 5o per cent. of our total imports from India in that year being so reexported.

The Indian mica can at present be exported to London only, and the mica in German East Africa is now being worked for, and obtained by, the Ministry of Munitions. Thanlss to these measures, and to the necessities of war, the British electrical industry has taken the place previously held by Germany and Austria, and is now the first in the world.

The demands for mica for the electrical industry are bound to increase, and the expected developments of commercial aircraft, wireless telegraphy, and motor traction make it essential that the Empire's supplies of this vital raw material should be safeguarded. The electrical industry is bound to be of such importance to the future industrial development of this country that we cannot afford to take risks with the valuable raw. material of mica, with which the Empire has been so bountifully endowed.

Tungsten.-Tungsten is essential to the manufacture of high-speed steel, and high-sneed steel is a vital war material. Tungsten is also used in the manufacture of metallic filaments for electric lamps, in certain appliances for wireless and other electric uses,

1 From an address to the Industrial Reconstruction Council on Friday, November 29, 19r8, by Mr. F. G. Kellaway, M.P., Parliamentary Secretary to the Ministry of Munitions. where to some extent it has taken the place of platinum, but its principal use is in the production of high-speed steel. Before the was the British Empire produced 40 per cent. of the wolfram-ore from which tungsten is made, but so successfully had Germany captured the trade that no British manufacturer was able to establish the industry in this country. Germany owed her great superiority in munitions production in the earlier stages of the war to the success with which she had captured the industry of tungsten production. All that has been changed. We are now able to produce all the high-speed steel needed for our own industries and to export at a reasonable price to our Allies. British manufacturers are now in a position to deal with all the British Empire production of ore, and could, if necessary, convert the whole world's output into tungsten metal or ferro. tungsten.

Ferro-chrome,-Ferro-chrome also is an essential material in the production of certain classes of steel. Alloyed with steel it acts as a toughener, and is used as chrome-stecl for armour-piercing shells, in armourplate, and for the wearing parts of aeroplane engines and gears in motor vehicles. For peace purposes it will be largely employed for such various purposes as motor parts, stainless cutlery, and rustless steel.

Before the war the United Kingdom production was practically negligible. We have now established at Newcastle-upon-Tyne a plant sufficient to meet our requirements for many years to come. Previously we imported our supplies from Norway, where it was produced by hydro-electric power. At Newcastle the power is obtained from the waste gases from cokeovens, and the industry will be in the unique position of competing successfully with the cheap water-power of Scandinavia.

Spelter.-Spelter (or zinc, to give it its correct name) occupies the third place in point of importance amongst non-ferrous base metal. The world's consumption in $\mathrm{r}^{\mathrm{I}} 3$ was $\mathrm{I}, \mathrm{OI} 2,000$ tons, as compared with copper $\mathrm{I}, 044,000$ tons and lead $\mathrm{r}, \mathrm{Iq} 6,000$ tons. It is an essential material in industry in the making of a large number of domestic articles and in building construction. Its main uses are for galvanising or coating iron and steel to prevent rusting, and for mixing with other metals to form brass, gun-metals, and other alloys. It is also rolled into sheets for roofing and electrical purposes. The oxide of zinc forms, next to white lead, the most important pigment. It is an indispensable compound of manufactured rubber, and is extensively used for medicinal purposes.

The British Empire is fortunate in possessing in Australia practically unlimited supplies of zinc ore (concentrates), these being amongst the largest in the world. For reasons which it is not my present duty to examine, Germany obtained control of these important ore supplies. She imported from Australia a large portion of her supplies of zinc ore, and on these was able to extend her important zinc industries.

Our own position previous to the war was that we used annually 240,000 tons of spelter in various forms, of which 77 per cent. was imported-practically all from Germany, Belgium, and Holland-Germany being the largest exporter to this country sending us in $1913 \mathrm{I}, 500,000 l$. Worth of spelter, besides smaller values of sheet-zinc, zinc oxide, and lithopone.

On the outbreak of war these supplies ceased, and we were faced at the same time with a tremendously increased demand for spelter to be used in the making of brass for fuses, cartridge-metal, and so on. Our immediate necds were principally met by imports from North America. The price bounded up from 23l. per ton to rasl. per ton. This figure led the U.S.A.

NO. 2570 , VOL. IO2] 